\title{
Magic bullets vs community action: the trade-offs are real
}

\author{
John B Mason ${ }^{1}$ and Barrie M Margetts ${ }^{2}$ \\ Introductory paper for 'magic bullets vs community action' workshop, \\ WPHNA, Cape Town, Tues 30 August 2016
}

\begin{abstract}
Magic bullets refer to single interventions, vertically delivered (i.e. from the centre), expected to have a dramatic effect, and often in practice circumventing or displacing more locally appropriate and sustainable activities. Once policies have defined intended outcomes - here childhood malnutrition is considered - decisions on programme specifics should take full account of trade-offs (including opportunity costs), and these decisions at present are often unduly influenced by vested interests. Magic bullets have times-and-places where they may be effective. These may get superseded, for example with changing disease patterns or other conditions, or because of new technologies. Regular transparent assessments of current applicability, with some estimate of benefits and costs, are essential, but uncommon.
\end{abstract}

Six examples of single purpose interventions are summarized considering times-and-places: protein supplements, infant formula, high dose vitamin A capsules (HDVAC), the vitamin supplement industry, ready-to-use therapeutic foods (RUTFs), and oral rehydration therapy (ORT). HDVAC and RUTFs are compared to community-based nutrition programmes. Protein is rarely the binding constraint in preventing or treating infant and child malnutrition. Infant formula is hardly ever to be preferred to breastfeeding; and in poor countries with inadequate hygiene its use carries much increased mortality risk. HDVACs were shown to have a mortality impact in the 1980's and early 90's, leading to global programs now covering a reported 200 million children; however recent studies have shown that this effect is no longer seen, but policies and programmes have yet to change in most countries. The vitamin supplement industry is included as it contributes to misguided views of nutrition and health, which should be mitigated. RUTFs are very useful for the narrowly defined group of children with severe acute malnutrition still with an appetite (most severely malnourished children have a poor or zero appetite, and require liquid diets first). However, the off-label use of these sweetened peanut butter pastes for moderately (or less) malnourished children is becoming widespread: it has many immediate and long-term disadvantages, including on children's food preferences; local foods, maybe enhanced with micronutrient mixes, are far preferable, including for rehabilitation of severely malnourished children. Oral rehydration provides a further example of where local solutions are preferable - but still seldom applied. Community-based programmes have known effectiveness, are more sustainable than magic bullet approaches, and in all the examples above can contribute to local problem solving.

\footnotetext{
${ }^{1}$ Prof. Emeritus, Dept. Community Health and Behavioral Sciences, Tulane School of Public Health and Tropical Medicine, New Orleans, USA

2 Professor, University of Southampton
} 
The implications for resource allocations are that shifting resources from magic bullet programmes to local, community- (and facility-) based activities will have many advantages. While cost estimates are hard to find, it seems that some such as HDVAC cost around \$1 per child per year, and RUTFs for SAM around \$5 per child per year (in the overall population; per SAM case treated the estimated cost is more than $\$ 100)$. Effective community-based programmes cost about \$10 per child per year, but address not one but most of the nutrition problems faced by children in those communities. Major donors have allocated $50 \%$ or so of their budgets to such supplies, and these funds go to the manufacturers in the rich countries, not to the countries in need. Allocation of resources to the countries themselves, and to local activities, could amount to billions of dollars, leading to improved nutrition, if single purpose interventions like HDVAC and RUTFs were no longer soaking up time, efforts of frontline workers, and funds.

\section{What problems are we trying to solve?}

The start of any analysis must be to ask the question what is/are the key public health (population level) problems, and what is/are the most effective practical (not just in theory or in unrepresentative sub-sets) ways to address these problems in a sustainable way. There may be sub-sets in the population with different challenges that may need specific focused attention differing from what is required for the population at large. Where severe acute malnutrition (SAM) or a severe nutrient deficiency is a problem this should be addressed in the short term, while deciding how to prevent it in the longer term.

The aim should be to achieve optimal overall nutritional status (in the widest sense of growth, health, and biochemical normality) to optimize function, and not just an increase in one measure alone such as micronutrient level in blood, or stunted growth. Good nutrition now must also include the avoidance of excess energy and non-communicable diseases (NCDs), and take into account the impact of poor/good nutrition at one stage of life on subsequent stages, and across generations. What happens before and during pregnancy has short and acute as well as longer and chronic effects on nutritional health of both the child and the mother. Moreover, a stunted child may respond differently to an intervention than a wasted child.

Where there is a specific cause, a specific solution may work, but it is likely that for many nutritional problems the causes are complex and thus require a number of interventions, in order to address the possibility of a number of rate limiting factors, and take account of interactions (Mason, Potts et al. 2015). In low-income settings, apart perhaps from iodine deficiency, it is rare that there is only a single nutritional problem. There are likely to be several, both identified and unknown. Pragmatically, a varied diet that supplies a range of ingredients that are beneficial, even if we don't always know how they work, is the best approach, rather than trying to pick one of the individual nutrients to focus on.

Perhaps all too often programmes are not properly and independently evaluated for their impact on the key outcomes. They are almost never evaluated to determine if solving one problem may have created or worsened others (for example, sugar fortification). Evaluation is often limited to short-term indicators, or measures of coverage rates. A WHO review of nutrition policy, 2006 shows that for most countries implementation is weak and poorly coordinated, often because of a lack of staff skills, time and funds. "Money should not be wasted on seeing if things work; we 
know they work, so let's just get on with it”, is often the position of funders. Indeed, to obtain funding in the first place, nutrition programmers must sometimes over-emphasize how well understood solutions to nutrition problems are.

Having decided on the outcome, the question is then about how to achieve this. Here philosophical differences and the potential for conflicts of interest do arise; these can cloud the discussion.

Discussions often start with recognition of the longer term desirable approach, expressed as improving nutrition security/reducing poverty/improving the sustainable access to quality diverse diets, but soon turn to arguing for short term interventions to address immediate needs. Unfortunately, history shows that these short term 'quick fixes' become institutionalized and continue into the long term, so that the original aims of addressing basic and underlying causes remain neglected and unmet. Indeed, far too often, large-scale funding of short-term solutions creates a vested interest that will work against shifting those funds to long-term solutions.

The nature of population-based community development involves multiple overlapping interventions where it is hard to determine exactly how each component works and contributes to the overall effect. This applies to efficacy trials and even more to programme effectiveness evaluations - but these remain crucial for developing effective programmes. Randomized controlled trials (RCTs) of single (magic bullet-type ${ }^{3}$ ) interventions are much easier to design and evaluate, and are more attractive to funding bodies because they feel more assured that they will get an answer to a narrow specific question. The fact that the question may not really be relevant or at least deserve the highest priority is often overlooked by funders. Results of evaluations of complex community interventions are often hard to get published -in part because they often raise more questions than they answer. Funders and editors tend to be drawn toward RCTs with straightforward answers.

Vested interests clearly shape the process and approach and it is now only beginning to be widely discussed that these conflicts are really critical.

\section{Some experiences}

There are trade-offs between the magic bullet approach, and alternatives which always involve local resources and individual and community empowerment. Some principles involved are suggested as follows:

- there are times-and-places where an intervention is useful, not useful, and counterproductive ("to everything there is a season...")

- whether an intervention fits with the times-and-places of established effectiveness needs to be objectively assessed, based on evidence

- as new understandings emerge, this assessment must be updated

- unintended consequences must be part of this, both for the individual and at population level

\footnotetext{
${ }^{3}$ Magic bullets refer to single interventions, vertically delivered (i.e. from the centre), expected to have a dramatic effect, and often in practice circumventing or displacing more locally appropriate and sustainable activities.
} 
- equally indirect benefits and risks, and opportunity costs, should be considered

- there must be transparency regarding vested interests and conflicts of interest.

Examples discussed below are: protein supplements; infant formula; high dose VA (HDVACs); ready-to-use-therapeutic foods (RUTFs); the vitamin supplement industry; oral rehydration therapy (ORT).

\section{Protein}

The history of considering protein of special importance in child malnutrition is revealing, and is roughly as follows. Colonial medical workers in Africa and the Caribbean identified the syndrome of kwashiorkor as a substantial contributor to under-five mortality rates (U5MR), in the 1950s and 60s (MacGregor, Tomkins et al. 1992). The more commonly observed child thinness, in severe cases marasmus, was noted but readily understood, and medically usually considered together with infection (diarrhea and measles especially) (Scrimshaw, Taylor et al. 1968). Further, maybe by chance in Africa (or maybe reverse causality), attention was focussed in the areas where non-cereals — bananas, cassava, yams, etc. — were the staples (Uganda, Nigeria); and these are indeed low in protein. Kwashiorkor was marked by low serum albumen and oedema, which fitted protein deficiency. In controlled conditions, high protein intakes reversed or prevented the disease.

When the high carbohydrate (CHO) diet was adequate in energy, increasing protein made sense in principle. But when a diet is inadequate in energy - quite common - protein may be used for energy rather than improving protein status (Miller and Payne 1961). Thus, on a population basis, securing access to enough food with say $10 \% \mathrm{kcal}$ from protein, and enough fat, was the most effective prevention, along with control of infectious diseases. No special attention to protein was needed, as all diets except those where starchy staples were high in children's diets making up only about $5 \%$ of poor countries food supplies - could provide this. Moreover, later research indicated that amino acid requirements, including for essential amino acids, may have been over-estimated. By 1970 the pathology, prevention, and treatment of kwashiorkor were all known adequately to deal with the problem; but entrenched research, along with development and small-scale testing of high-protein toddler foods, continued.

These developments took a long time, involving much defense of positions. In the scientific community, rearguard actions continued, leading to investment in approaches that established evidence correctly predicted would not work (e.g. lysine fortification). Institutionally, the Protein Advisory Group of the UN (1973-1977) pushed by powerful scientific figures, became the institutional focus; this then became the UN ACC-SCN (UN Sub-Committee on Nutrition). The food industry developed a range of high protein foods, often from exotic sources such as single cell organisms, fish protein concentrate, and even petroleum. Agricultural development projects were seen as nutrition-oriented if they produced protein, even if indirectly as animal feed. The dairy industry fueled (and was fueled by) school milk programmes. Surplus dried skim milk became a major food aid commodity and was reported to disrupt breastfeeding, even in conditions of extreme deprivation. To this day, we nutritionists have to spend time explaining why protein deficiency is not usually the problem. 
There was a place for specifically providing protein — as opposed to just providing more and better food - but it was confined to children in a few countries with limited diets, and probably is more so today. In malnutrition prevention, ensuring that starchy staple cultures improved infant and young child feeding (IYCF) practices (e.g. optimal breastfeeding and adding groundnut sauces earlier) would be the way to go; special food supplements are unnecessary except if food supplies are interrupted or in extreme poverty. And in these circumstances overall food access and addressing poverty are still priority. In treating severe malnutrition, protein remains a consideration, but is not a binding constraint; energy density for instance, and total energy intake and micronutrients are.

It was not so much that evidence for the minor role of protein in child malnutrition - proteinenergy malnutrition (PEM) in fact — was ignored, as it was downplayed. Much of the research focus was on this rather small aspect of the overall problem of child malnutrition, due in part to professional interests of the biomedical research community, the support payoffs to be had, and a high profile to African-based research. That perspective was slow to change. In the 1990's we were greeted by incredulity in some UN quarters when the UN sub-committee on nutrition (SCN)'s report on the world nutrition situation (RWNS) reported that child malnutrition was more prevalent in S Asia than sub-Saharan Africa (SSA). But information like that helped to shift opinions within the UN and donor communities, and eventually more broadly.

The consequences of the protein - and biomedical focus generally - undoubtedly delayed more effective approaches to PEM itself, as well as distorting approaches in agriculture and economic development towards supply over demand and food quality over quantity. To this day it is not always accepted that the usual nutritional effect of agricultural development is to increase incomes among the poor; the demonization of cash crops was an example of that. Agricultural and health/nutrition policies are not adequately connected, globally or nationally.

Vested interests pervade this topic. For example, in some countries school milk programmes absorb budgets (sometimes under a 'nutrition' line), justified as an ideal food for school children. It isn't ideal, especially if the children are hungry, and it has a high cost/kcal. But the dairy industry can have excellent government ties.

\section{Infant formula}

Infant formula is rarely justified except in very limited cases. A time and place probably never existed when it was appropriate. Orphanages in past centuries had up to $90 \%$ infant mortality (Milner, Duke et al. 2013), from diarrhea related to artificial feeding; it has been identified as infanticide. Its cause may at least have been suspected, as orphans in private well-off care would often have wet nursing and do well. The 'biggest uncontrolled experiment in human history' (Minchin 1987), artificial feeding of infants, has seldom been looked at squarely, and the advice available today varies wildly, as any parent knows.

To be fair, for many years now nutritionists have been consistent on the problems of infant formula, and the problems of promoting good practice lie elsewhere. This is case of vested interests and inadequate institutional checks and balances, and it's worth a brief look at the lessons. 
WHO, and the World Health Assembly (WHA), are recognized in principle as the focal point for dealing with such issues; but how, exactly? The International Code of Marketing of Breast-Milk Substitutes and follow up WHA resolutions provide reasonable guidelines, but are voluntary and open to overt and covert undermining, especially now on the unregulated internet. But further, WHO itself is being systematically (and not coincidentally) weakened. For example, only 18\% of its current budget is assessed contributions (equivalent to hard money, core funding); the rest is earmarked from donors from OECD governments and massive private funds like the Bill and Melinda Gates Foundation (BMGF). These funders determine what WHO does far more than the constitutional procedures of the WHA. So only a tiny budget is for the Code, and not much can be done. This is a usefully clear example both of the weakness of any international guidance; and of how even that is largely ineffective. Effective international institutions do not exist to deal with the risks from using formula in poor countries.

High dose vitamin A capsules (HDVAC)

While this case is discussed in a conference paper (Fisker and Greiner 2017), drawing some of the historical parallels to the other cases may be useful here. The HDVAC problem is not unique but part of a pattern - to the point that both protein and VA have been referred to by respected scientists as 'fiascos' (McLaren 1974; Latham 2012).

Scientific understanding of vitamin A (VA) evolved normally for the first half-century or so since its discovery and characterization in the 1920's as the 'anti-infective' vitamin. Since VA is stored in the liver, the possibility of preventing blindness due to VA deficiency (VAD) by giving a high dose that would be stored and give long term protection from blindness was tested. This had a high efficacy, for example in studies in India.(Sinha and Bang 1976). Expanding the testing to Indonesia (without placebo, to note) (Sommer, Tarwotjo et al. 1986) led to the now well-known chance finding that child mortality appeared to be drastically decreased — and, with several additional RCTs found an average impact of $23 \%$ on young child mortality (Beaton, Martorell et al. 1993). The rest is thought to be history.

However, the full, updated story is an object lesson of how agencies and bureaucrats blindly ran with this from 1990 on, with no evaluation whatsoever by the programme managers and donors (Mason, Greiner et al. 2015). So not until 1999-2001 was an evaluation of an operational programme done ('DEVTA in India'), and, after being reported at a meeting in 2007, this suffered extraordinary delays before publishing the finding of no impact on U5MR in 2013 (Awasthi, Peto et al. 2013). This was soon to be followed by similar results from Africa. Within recent research, a key finding was that only unvaccinated children were thought to benefit; and of course the solution for them is to catch up with the vaccinations, not to give a highly unphysiological dose of unproven safety (Benn, Aaby et al. 2009).

Worse was to come: efforts were intense to invalidate these last mentioned results, and to impugn those (not only one of us) asking questions as to why 200 million children were reportedly being dosed twice yearly, with significant opportunity costs, with something that no longer seemed to be working to achieve its stated goal (Mason, Greiner et al. 2015). Proponents — both scientists and policy-makers — took steps to prevent the integration of the new findings 
and their implications into policy (West, Sommer et al. 2015) (Mason, Greiner et al. 2015) (correspondence).

Where, probably in remote areas, blindness from (vitamin A deficiency (VAD) is still occurring, HDVACs could still have an emergency stopgap role. But that is probably the extent of the time and place where it should be used these days.

So here we have an intervention which had a place and time of utility, which is now probably largely past. This is coupled with a refusal of 'stakeholders' (a bad concept in the first place) to adapt. Do they have anything to lose? That is where the danger and foolhardiness of 'privatepublic partnerships' comes in; and the seduction of public sector bureaucrats, whose obligation for objectivity is undermined.

Here, as for protein, a paradigm shift was needed, and is occurring. In fact, observing how this happens - with parallels to Kuhn's concept — is itself going to be instructive (and publishable).

The trade-offs here are first the opportunity costs, both financial and in terms of using valuable time of frontline health workers. Second, although HDVAC programmes do not and cannot make more than temporary improvements in vitamin A status, the existence of HDVAC programmes has undoubtedly inhibited and held back development of more effective and sustainable approaches toward improving vitamin A status, which should ensure regular intakes at physiological levels: improved diets and food habits, fortification, sprinkles, and so on. Shifting priorities and attention away from HDVAC would free up resources for use in more effective methods, for VAD and more generally for child malnutrition.

An anecdote: in 2012 it was announced at a large meeting at MI that the Canadian government had just committed a further many millions of dollars to VAD; one of us asked if this was fungible and could be spent on a variety of approaches. Clear and immediate answer: no, it must be spent on HDVAC. It would be instructive to know on whose advice this political decision was made.

\section{Vitamin supplement industry}

This is included as it is another example of misuse of science for (in this case) private sector marketing. There are many quasi scientific misconceptions allowed to flourish. One overriding one is that if this much is good for you, then twice as much must be twice as good; and anyway there is no harm. One needs to explain that the human body is more like a car, which does not go twice as fast on a full tank as on half a tank.

This raises issues of how requirements are calculated, and how we have moved from deficiency prevention based on physiology, to a 'functional outcome or clinical preventive outcome of vitamins' where higher doses are said to have additional functions. In fact, there is now some evidence that if you are marginally nourished in terms of energy, giving higher levels of vitamins may be counterproductive.

One tradeoff is financial — quite a lot can be spent on supplements, which could be much better spent on good foods. But another is the perception that vitamins and minerals can act as magic 
bullets - moreover in the absence of any signs of deficiency — and somehow improve (e.g.) nerve function or other specific but ill-defined conditions (often loosely related to signs of severe deficiency, like pellagra or beriberi, which have not been seen for years in communities where some people use supplements - but not because of the supplements!). This must embed a wrong perception of health, and distort health-seeking behaviors.

\section{Ready to use therapeutic foods (RUTFs)}

Treatment of severe acute child malnutrition as in-patients, often in special nutrition rehabilitation centers, was established in the middle of the $20^{\text {th }}$ century in several low-income settings. Liquid diets were usually essential as many children had little appetite, often needing to be fed by a naso-gastric tube. As the child recovered, usually within one to two weeks, appetite returned and the child was largely out of risk. At this point it could be moved with caution onto a high energy semi solid diet, which if appropriate would be eaten with increasing enthusiasm, leading to rapid catch up weight gain and recovery. This applied whether or not the malnutrition was causing edema, though kwashiorkor is associated with higher risk and requires more careful treatment.

RUTFs were originally intended for the narrow window when a child was severely malnourished, and had enough appetite to eat semi solid foods. They could not replace the liquid diets needed if there was no appetite. The criteria should include when the child has an appetite but for some reason high quality and high energy meals (from good oil content, and low water and bulk) are not available from local foods. Such conditions do exist, but all too often no attempt is made to have such meals available.

A common situation is: "that's all that was available" — but was that because no effort was made to use local foods? Early in an emergency this may be so, but then should transition to local foods. In non-emergency situations it is very doubtful if imported sweetened peanut butter (the usual formula) is needed; moreover there are many harmful effects, discussed in (Bazzano, Potts et al. 2017) and (Shukla and Marathe 2017). Issues of enhancing available family diets are also discussed in the conference paper (Bazzano, Potts et al. 2017).

Another anecdote, of which many of our colleagues have had similar experiences: picture an upcountry outpatient clinic, a mother with a very thin 2-year-old, who is clutching a dirty empty plastic tube which once contained RUTF.

You ask: "What does your child get to eat?"

"Plumpynut, but it ran out a week ago" is the reply

“Then what else?”

"Nothing, he only eats plumpynut, which we get every two weeks". No wonder the child is now dangerously wasted.

Further, RUTFs are being promoted for child feeding in the absence of acute malnutrition, displacing traditional meals. This is quite inappropriate 'off label' use, but there is little regulation. 
RUTFs were no doubt initially a well-meaning idea, with a narrow but useful time and place. But now they have become both thoughtlessly applied, and have given rise to substantial corporate involvement, and profit, largely from inappropriate use and likely causing long term damage. Astoundingly it is reported that some NGOs dealing with emergencies recommend supplying RUTFs, which they then themselves manufacture, at a cost to the donors! This has a very clear conflict of interest which obviously should be dealt with.

Here again there are important trade-offs. It is clear a better use of the considerable funds used by the international agencies to buy, ship, and deliver RUTFs, by the ton, would be to apply them to alternative interventions, including prevention of child malnutrition. Second, using local foods has so many advantages, including that children like to eat them, and more so if they contain more oil and preferred tastes: there is little difficulty in replacing lost weight fast if the supplementary food is delicious. (We showed this in 1974 (Mason, Hay et al. 1974) — Lancet Mason et al.)

Further, many disadvantages for children's health and nutrition can arise from accustoming children to sweetened peanut butter paste - this is addressed in the paper by Bazzano et al (Bazzano, Potts et al. 2017). A recent paper from India convincingly highlights many of the problems of RUTFs, and their implications, in Maharasthra (Shukla and Marathe 2017).

The Annex at the end of this paper gives some estimates of RUTF costs for treating SAM. Treating one case is about $\$ 100$. If $5 \%$ of the child population experiences SAM, then this is about $\$ 5$ per child over the population. This can be compared with costs of prevention, through community-based programmes at about $\$ 10 /$ child/year. If the funds and effort went into prevention, rather than waiting for SAM cases and then treating them, the entire child population would benefit.

\section{Oral rehydration therapy}

This topic has been effectively covered in 'Questioning the Solution'(Werner and Sanders 1997), and is referred to here as another well documented and well-aired magic bullet discussion. To be clear, we refer mainly to pre-packaged, usually imported, oral rehydration salts. The story has many analogies with, for example, HDVACs.

In the 1950-60's it was found that adding glucose (or other metabolizable carbohydrate) to rehydration fluids enhanced the active absorption of sodium and potassium thus increasing their effectiveness, within limits of osmotic effects (which were much better dealt with in the neglected practice of giving so-called home fluids such as rice water, which has starch - more energy per osmole). Clinicians got better results with such rehydration fluids, and they made oral rehydration a lot more practical (but still not that easy).

One good example showing the option of local action comes from Brazil in the 1980's. Ten million plastic spoons for making homemade oral rehydration solution were distributed across the country. The spoons were produced (and donated) by a toymaker in Sao Paulo, using a mold obtained from Teaching Aids at Low Cost (TALC), and then distributed with help from UNICEF to various community based health care movements in the Northeast of Brazil especially. These included the Pastoral da Crianca run though the Roman Catholic Church and the village health 
agents belong to Family Health Program of the Ministry of Health. The village heath agent programme which started in the north east spread across the rest of Brazil as the Family Heath Program in the nineties. An evaluation done in 2005 found that this was an important contributor (but not the only one) to reducing infant mortality (Macinko, Guanais et al. 2006).

The approach rapidly escalated in the 1980s, as a pillar of the child survival revolution, the $\mathrm{O}$ of GOBI (growth monitoring, oral rehydration, breastfeeding, immunization: the strategy for child survival), and the example Reagan needed to show that the private sector could even take on problems linked to poverty. Undoubtedly many lives were saved. But again, the local option of home fluids or local ORS production - was largely ignored or swamped (with the exception of Brazil). Scientific criteria were distorted - as little research had been done on local solutions, it was claimed that as they were not known to be effective, they were presumed to be ineffective, rather than that their (likely) effectiveness had not been adequately researched - a classic publication bias. So, opportunities were missed, donors were pleased, and industry benefitted.

\section{Community-based programmes (as an alternative)}

The two sides of the ledger can be seen as allocating resources for magic bullets or for community programmes, although these are not entirely comparable. Two papers in this issue on community based programmes gives details, supporting our conclusion that these are the best approach, based on experience, to tackling childhood malnutrition (Shantha and Shrimpton 2017) (Doherty and Oliphant 2017).

First, the reasons why this really IS a trade-off - rather than considering one can have it both ways - are simply that resources are scarce and are competed for. This is true both within the 'sector', and between sectors. Here it probably involves opportunity costs as much as direct costs: to be specific, magic bullets require resources far beyond the supply costs - which are often minor - in terms of personnel and organizational time, travel, etc. Such costs have been estimated for child health days (Verguet S 2013), plus the effects of these in hurting regular health services. And these disproportionately affect the poorest countries and the weakest health systems.

So one issue is how best to use available resources, in budgetary and opportunity terms. A second concerns the balance of advantages and disadvantages.

The benefits of the alternatives, of community- and facility-based activities (WHO 2010), (World Health Organization 2013) (often these need to be taken together for operations, even if under different budgets) are suggested in Table 1 . These advantages and disadvantages are not fully comparable between the single magic bullet interventions, but reasonable comparisons can be made, for example as follows, concerning the magic bullets consuming most external resources at present - HDVAC and RUTFs. Table 1 provides a quick tabulation of some advantages and disadvantages of HDVACs and RUTFs. Interestingly, but inevitably, the common feature is that magic bullets lead to the transfer of development assistance resources to industrialized country corporations. Community based activities are included in table 1, and added to these advantages and disadvantages is their function as a route or platform for a wide number of interventions, some of which are illustrated in table 2. 
High dose vitamin A capsules (HDVAC: table 1A) had their time-and-place, but this is mostly past now (Mason, Greiner et al. 2015), particularly as immunization now has high coverage in poor countries, including in SSA. Nonetheless, viewing advantages and disadvantages is instructive. HDVAC programmes illustrate many of the attractions of vertical donor-driven interventions. For instance, they can use existing health personnel - although crucially the opportunity cost is substantial, and not often considered.

However, today there is no evidence for impact on child mortality, and indications of possible increased mortality in certain groups, as the HDVAC may interact unfavourably with vaccines and other factors (Benn, Aaby et al. 2015).

Alternative approaches to vitamin A deficiency (VAD) are also illustrated in table $1 \mathrm{~A}$ - from local foods, in which vitamin A and precursors (beta-carotenes) are usually present. If the vitamin A content is low, consideration can be given to either adding VA to these (e.g. adding fortified foods or using 'sprinkles') These have advantages over HDVAC, in terms of e.g. sustainability and less reliance on outside sources (last row of table 1A); and can have positive benefits in encouraging and supporting diets based mainly on local foods.

RUTFs are described in detail in (Bazzano, Potts et al. 2017), from this same conference. Some of the key points in this context are in table 1B. First, it should be stressed that providing a good quality therapeutic diet to severely malnourished children with enough appetite to meet high kcal requirements is essential; and RUTFs have a role here. However this role is narrow, as many severely malnourished children do not have sufficient appetite. Had providers of RUTFs stuck to this role there would be less criticism. Notwithstanding this, locally prepared foods - local children's diets, probably enhanced with additional kcals (e.g. as oil) and micrountrients (e.g. as 'sprinkles') - should be preferred wherever feasible to imported packaged blended foods (particularly sweetened peanut butter). The risks to children's developing food preferences is one example of possible actual harm from RUTFs; prolonged use could even be a risk for future obesity and associated diseases (again see (Bazzano, Potts et al. 2017) .

Thus local high energy foods have many advantages (table $1 \mathrm{~B}$, second section), not restricted to use in severe malnutrition. Inputs are required to foster this, including possibly hiring local women to cook in emergency settings (usually there is no shortage of experienced cooks, benefitting here from employment). In non-emergencies, better IYCF practices include preparing higher energy and probably micronutrient-enhanced diets, and this should come within the normal programmatic support, preferably through community-based activities.

Advantages and disadvantages of community-based programmes are illustrated in table 1C. One of the key characteristics should be that community workers are familiar to the local people, and ideally should be drawn from among them. The combination of community- and facility- based capacity provides a platform, or a route for delivery, for many relevant interventions, as suggested in Figure 1, which includes other routes for completeness. Community-based programmes provide a basis or support for many interventions. 
Table 1. Comparison of advantages and disadvantages of HDVAC, RUTFs, and community-based programmes with alternative interventions.

\section{A. HDVAC compared with dietary options}

\section{Advantages}

HDVAC

- Programme quickly set up

- Only needs action every 6 months

- Can draw on existing personnel

\section{Disadvantages}

- Ineffective

- Opportunity cost

- Possible harm

\section{Promotion of increased production and regular intakes of VA/carotenes in diet} (unfortified)

- Fosters good local food habits

- Safe and sustainable

- Benefits local economy
- Improving diet takes time, local expertise, and effort

\section{Increased intakes of VA/carotenes in diet (fortified)}

- Once established fairly sustainable and low cost
- High initial cost, high levels of expertise of several kinds required, and political effort

- Monitoring needed

\section{Characteristics of this magic bullet (HDVAC)}

- Seems easy, but not sustainable

- May be efficacious in clinical trials but often not effective in real life or even necessary

- Always requires external resources

- Development assistance resources go to first world corporations.

- Distracts government and donor attention from broader more sustainable approaches 


\section{B. RUTFs compared to local foods}

\section{Advantages}

\section{RUTFs}

- Readily available in pre-packaged form

- Effective provided malnourished child has appetite

- Requires little time, effort or fuel expenditure by family

- Needs no refrigeration or preparation

\section{Disadvantages}

- Availability unreliable

- No use for severely malnourished child with no appetite (as is usual)

- Mothers tend to stop other foods

- Off-label use as supplement

- Establishes unfamiliar tastes

- Too much sugar

- Has a high renal solute load, requiring provision of extra safe water

\section{Local high energy foods}

- Familiar tastes

- Reinforces value of local foods

- Easily accepted as tastes delicious (if you try)

- Keeps resources local
- In emergency may be hard to get (unlikely)

- Need to set up local processing, or

- Need to demonstrate and have local acceptance.

- Usually requires home preparation, needing time, fuel, and knowledge

\section{Characteristics of this magic bullet}

- Effective but many drawbacks, including widespread misuse

- Always requires external assistance

- Development assistance resources go to first world corporations

\section{Community-based activities}

Advantages

Community-based (with facility-)

- Direct contacts between frontline workers (CHNWs) and families

- Platform for multiple interventions

- CHNWs familiar to families.

- Interventions make local sense.

- Tracking of at risk children

- Referral of sick/malnourished children

\section{Disadvantages}

- Workers often too few per family

- Incentives may be poor

- Training and supervision problematic

- High CHNW turnover

- Inadequate messages 
Table 2. Applicability of platforms to interventions

\begin{tabular}{|c|c|c|c|c|c|}
\hline Platform & HDVAC & Fortification & RUTFs & $\begin{array}{l}\text { Enhanced } \\
\text { local } \\
\text { foods }\end{array}$ & $\begin{array}{l}\text { Education } \\
\text { and } \\
\text { counseling }\end{array}$ \\
\hline $\begin{array}{l}\text { Health system: } \\
\text { local health post }\end{array}$ & $(+)$ & $(+)$ & + & + & + \\
\hline $\begin{array}{l}\text { Community-based } \\
\text { nutrition/integrated } \\
\text { programmes }\end{array}$ & $(+)$ & $(+)$ & + & + & ++ \\
\hline $\begin{array}{l}\text { Campaigns. Child } \\
\text { Health Days, } \\
\text { emergencies }\end{array}$ & + & -- & + & $(+)$ & $(+)$ \\
\hline $\begin{array}{l}\text { Central, vertical } \\
\text { (or diagonal) } \\
\text { programmes }\end{array}$ & + & + & + & $(+)$ & -- \\
\hline
\end{tabular}

\section{Implications for trade-offs and resource allocations}

A key point in deciding between policy alternatives concerns: who benefits? There is little doubt that donors' preferences are skewed towards the supply side, where funds flow to industrialized countries. The World Bank's 'Repositioning Nutrition ...' (World Bank 2006) publication, as well as the first notional budget for the Scaling Up Nutrition (SUN) initiative, proposed that over half the funds estimated for nutrition globally should go to industrialized world suppliers - in line with the preferences for magic bullets.

Estimates for resource implications have omitted consideration of the routes or platforms through which people will have access to the interventions, which are significant, and often the main cost (e.g. HDVAC). This was largely true of the World Bank's 'Repositioning Nutrition ...' exercise in the early 2000's, and for the (in)famous Lancet nutrition series (all efficacy, no effectiveness, hence no real costing possible). On the contrary, if we know how to reach people and can help fund it, then all manner of interventions can be slotted in. Here, facility- and community-based platforms and the associated frontline workers are the relevant routes. In assessing costs, a rough comparison is that effective community-based programmes are estimated to cost about \$10/child/year (World Health Organization 2013).

Estimates of costs for HDVAC are in table 3, and RUTFs in the Annex at the end of this paper. For vitamin A, the cost of HDVAC is a few cents per child; as noted above, it is the delivery system that is the main direct cost (leaving aside here the opportunity cost), which may amount to \$1-2 per child per year. RUTF costs are proportionately more for supplies of the packaged product, whether locally produced or imported, and should include distribution and treatment costs; cost per SAM case approximately $=\$ 100$.

We have estimated that effective community based programmes are characterized by the community worker to family ratio: about 1:10-20 for part time volunteers, about 1:100-200 Full 
Table 3 Resources for Vitamin A

\begin{tabular}{ll}
\hline Source & Estimate \\
$\begin{array}{l}\text { "Repositioning Nutrition ...” } \\
\text { (World Bank 2006) }\end{array}$ & $\$ 750 \mathrm{~m}$ for 200m children, about \$2/child/year \\
$\begin{array}{l}\text { GiveWell /Quoting } \\
\text { (Daulaire, Starbuck et al. 1992) }\end{array}$ & Total \$0.8 (current\$)/child/year \\
$\begin{array}{l}\text { MI/UNICEF (2007-2016)(MI 2016) } \\
\text { (UNICEF 2007) }\end{array}$ & $\begin{array}{l}\text { (a) MI budget: HDVACs only, } \$ 10 \mathrm{~m} \text { annual, 500m } \\
\text { children, \$0.02/child/year } \\
\text { (b) } 1997-20162 \text { billion doses: HDVACs only, \$160m } \\
\text { @ \$1/child/year total costs, \$8 billion total, \$400m/year }\end{array}$ \\
\hline
\end{tabular}

Time Equivalents (World Health Organization 2013). This seems to be associated with about \$10-15/family/year - a figure we've used for 20+ years. Singh and Sachs recently estimated a cost of \$6.6/head/year (more than \$30/family/year) for community health workers for SSA, with broader responsibilities than child nutrition, but more treatment- than prevention-oriented (Singh and Sachs 2013).

Thus it would, for example, require similar resources to prevent child malnutrition through community actions, than to simply treat the children that become malnourished. Communitybased programmes benefit more children, and women, than treatment alone. The trade-off in committing resources to RUTFs (and CMAM) rather than community programmes is thus estimated to be a poor choice.

Trade-offs need to be seen in terms of appropriate actions for times-and-places. The time-andplace definition depends in part on the level of infrastructure development, of population education, and so on. One reasonable proxy is the position in the demographic and health (and nutrition) transition. When total fertility rate (TFR) is 7 or so, immunization and access to family planning may be the priority. When - as in much of Africa and all of Asia - the transition is well under way (e.g. TFR 3-4) a broader approach with higher priority for maternal and child nutrition may be feasible, through facility- and community-based programmes.

Questions concerning trade-offs are not just budgetary cost but importantly opportunity cost. There are far too few trained people at the frontline, and their time is precious. For example, running Child Health Days in South Africa was assessed by (Verguet S 2013) in terms of health worker activities, and found that clinic services deteriorated substantially for a month or so due to the reassignment of health staff. Such effects unfortunately will be more problematic for the weakest health systems, which tend to be in the poorest countries.

It's possible that inputs to community-based programmes are not needed forever. Certainly in the longer run, countries such as Thailand and Indonesia have pulled back on these as problems 
receded. In Africa (e.g. Ethiopia) as well as Asia the pattern that emerges when monitoring the prevalences of underweight (from weighing programmes) and stunting from evaluation surveys is of a rapid decrease in the first 1-2 years, of about 10 ppts, then a slower reduction of about 2 ppts/year (i.e. up to 30 ppts in 10 years). This success probably results from behavioural changes, and it is quite possible that these persist even with reduced external input. In other words, a community may experience long-lasting behaviour change after a few years of community action for child nutrition (e.g. in breastfeeding and other IYCF practices), allowing programme evolution.

The broad upshot is that large scale or national programmes (of which we assessed 60 in (World Health Organization 2013)) need funding targeted to the appropriate times-and-places. The periods are perhaps 20 years, and the time is when the demographic transition has started. Hastening the transitions is of wide benefit - including mitigating the population increase - and improved nutrition helps. To take the example of Ethiopia, recently about $\$ 65 \mathrm{~m}$ per year in donor funds was available for nutrition - amounting to about $\$ 5$ per child per year - approaching the amount needed for wide impact.

Effort that could be transferred from ineffective magic bullet programmes to community- and facility-based programmes would have the dual benefit of adding to finance available, and probably more importantly reducing the substantial opportunity cost in frontline personnel time, travel and so on.

This could amount to the equivalent billions of dollars if HDVACs and RUTFs were no longer soaking up time, effort, and donor funds. 


\section{Annex}

Resources used for treatment of severe acute malnutrition (SAM) with Ready-to-Use Therapeutic Foods (RUTF)

Prepared by Kaitlin S. Potts

Tulane School of Public Health and Tropical Medicine Dept. Global Community Health and Behavioral Sciences

Table. Examples of resources used for RUTF and outpatient treatment of SAM through the community management of acute malnutrition (CMAM) programme.

\begin{tabular}{|c|c|c|}
\hline Source & Estimate & Notes and Interpretation \\
\hline $\begin{array}{l}\text { PlumpyField. PlumpyField } \\
\text { with Nutriset: FAQ. } \\
\text { Available online: } \\
\text { http://www.plumpyfield.co } \\
\text { m/faq (Accessed 27 July } \\
\text { 2017) }\end{array}$ & $\begin{array}{l}\text { “The amount of } \\
\text { Plumpy’Nut@ needed for an } \\
\text { average 8-week outpatient } \\
\text { treatment costs about } \\
\text { US } \$ 50 \text { and puts the care in } \\
\text { the hands of the mother or } \\
\text { family caregiver.” }\end{array}$ & $\begin{array}{l}\text { This price refers only to the } \\
\text { amount of RUTF product } \\
\text { needed for an average } \\
\text { outpatient treatment of } \\
\text { SAM, and does not include } \\
\text { delivery and } \\
\text { implementation costs. }\end{array}$ \\
\hline $\begin{array}{l}\text { UNICEF. Ready-To-Use } \\
\text { Therapeutic Food Price } \\
\text { Data. 15 January } 2017 . \\
\text { Available online: } \\
\text { http://www.unicef.org/supp } \\
\text { ly/index_59716.html } \\
\text { (Accessed 27 July 2017) }\end{array}$ & 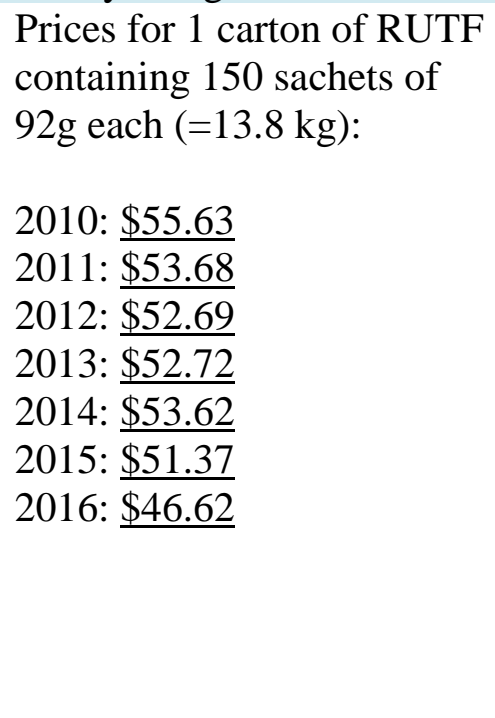 & $\begin{array}{l}\text { Prices are yearly averages } \\
\text { from all suppliers for orders } \\
\text { by UNICEF Supply Offices } \\
\text { and Country Offices. Prices } \\
\text { given in Euro's were } \\
\text { converted to USD using } \\
\text { yearly average exchange } \\
\text { rates available at IRS.gov }{ }^{4} \text {. } \\
\text { Cost per carton of RUTF } \\
\text { does not include post- } \\
\text { production transport and } \\
\text { implementation costs - } \\
\text { these prices refer to RUTF } \\
\text { product only. }\end{array}$ \\
\hline $\begin{array}{l}\text { UNICEF Evaluation Office } \\
\text { (2013). Evaluation of }\end{array}$ & $\begin{array}{l}\text { Figure } 6.1 \text { (p 61, of } \\
\text { reference quoted in first }\end{array}$ & $\begin{array}{l}\text { These prices are from } \\
\text { evaluations dating } 2013 \text { or }\end{array}$ \\
\hline
\end{tabular}

${ }^{4}$ IRS. Yearly Average Currency Exchange Rates: Translating foreign currency into U.S. dollars. 3 February 2017. Available at: https://www.irs.gov/individuals/international-taxpayers/yearly-average-currency-exchange-rates. (Accessed 31 July 2017) 
community management of acute malnutrition: global synthesis report. New York, United Nations Children's Fund.

Available at: https://www.unicef.org/eva ldatabase/files/Final_CMA M_synthesis_FINAL_VER SION_with_ExSum_transl ations.pdf. (Accessed on 27 July 2017)

\section{Emergency Nutrition}

Network (ENN):

Government experiences of scale-up of Communitybased management of acute malnutrition (CMAM). A synthesis of lessons. 2012. Available at: http://www.ennonline.net/c mamgovernmentlessons (Accessed on 27 July 2017) column) illustrates that RUTF (product alone) was about $50 \%$ of the total costs of CMAM implementation in Ethiopia. Other 50\% includes service delivery and transport, logistics, and other supplies and equipment.

Table 6.1 (p 64, of reference quoted in first column) gives the total cost per child for outpatient treatment of SAM in 5 countries: Nepal \$76.8;

Pakistan \$145;

Ethiopia \$110;

Chad \$196;

Kenya \$93.79

Average (from these 5 countries) cost to treat a SAM child via RUTF and outpatient treatment = $\$ 124.32$

\section{p. 41:}

"RUTF lies at the centre of the CMAM approach. $\underline{\text { It }}$ represents about half of the total costs for implementation, is a heavy and 'high value' product and the programme requires a constant supply." earlier. The cost of RUTF

has dropped slightly through time as shown in the above source in this table (UNICEF RUTF Price Data).

The average total price of treatment, including RUTF supply, transport, and all implementation costs of $\$ 124.32$ appears to be slightly higher than double the cost of RUTF alone (comparing to UNICEF RUTF Price Data prior to 2013).

The total cost of treatment is highly variable across these 5 countries and likely depends on many factors. The cost given for Ethiopia (\$110) is very close to double the cost of RUTF prior to 2013. This corroborates the first useful reference from this source, stating that RUTF product alone accounted for about $50 \%$ of the total costs of implementation. This statement also corroborates the assumption that RUTF product is expected to account for about half of the total cost of outpatient treatment of SAM children with RUTF. 


\section{Interpretation}

A carton with 150 sachets of $92 \mathrm{~g}$ each is assumed to be the approximate amount of RUTF needed for one outpatient treatment for one child suffering SAM. Treatments last between six and eight weeks and require between 10 and $15 \mathrm{~kg}$ of RUTF ${ }^{5}$. UNICEF pricing data and the PlumpyField website indicate that the production of this amount of RUTF costs about $\$ 50$. Therefore, $\$ 50$ is taken as the approximate cost of RUTF needed per one child treatment. Prices have declined slightly through time and actually averaged less than $\$ 50$ in 2016 based on UNICEF pricing data published in January 2017.

Factoring in costs for implementation and delivery approximately doubles the cost of treatment of SAM from the base production cost of RUTF. This is based off of the UNICEF 2013 Evaluation of CMAM and the ENN report of government experiences of scale-up of CMAM. The total costs varied widely among the five country case studies used in the UNICEF CMAM Evaluation, and looked to be slightly higher than double the cots of RUTF, but for this interpretation we will assume RUTF accounts for about half the total cost of treatment once transport and implementation costs are accounted for. This would give a total cost of about $\$ 100$ per SAM child per treatment.

Generally, a child is not expected to relapse, but may if the food security situation has not improved. Assuming the child does not relapse over the course of a year, the cost per year for the outpatient treatment of one SAM child with RUTF remains about $\$ 100$.

Assuming the number of children suffering SAM in LMICs to be around 5\% of total child population gives a cost per child per year of $\$ 5(\$ 100 * 0.05)$ for the total population of children. Assuming one child per household gives a cost of outpatient treatment of SAM with RUTF of approximately \$5 per household per year.

\footnotetext{
${ }^{5}$ World Health Organization, World Food Programme, United Nations System Standing Committee on Nutrition and United Nations Children's Fund (2007). Community-based management of severe acute malnutrition. A joint statement by the World Health Organization, the World Food Programme, the United Nations System Standing Committee on Nutrition and the United Nations Children's Fund.
} 


\section{References}

Awasthi, S., R. Peto, et al. (2013). "Vitamin A supplementation every 6 months with retinol in 1 million pre-school children in north India: DEVTA, a cluster-randomised trial." Lancet 381(9876): 1469-1477.

Bazzano, A. N., K. S. Potts, et al. (2017). "The Life Course Implications of Ready to Use Therapeutic Food for Children in Low-Income Countries." Int J Environ Res Public Health 14(4).

Beaton, G., R. Martorell, et al. (1993). Effectiveness of Vitamin A Supplementation in the Control of Young Child Morbidity and Mortality in Developing Countries. Geneva, Switzerland, Administrative Committee on Coordination/Subcommittee on Nutrition, United Nations.

Benn, C. S., P. Aaby, et al. (2015). "Neonatal vitamin A: time to move on?" Lancet 386(9989): 132-133.

Benn, C. S., P. Aaby, et al. (2009). "Does vitamin A supplementation interact with routine vaccinations? An analysis of the Ghana Vitamin A Supplementation Trial." Am J Clin Nutr 90(3): 629-639.

Daulaire, N. M., E. S. Starbuck, et al. (1992). "Childhood mortality after a high dose of vitamin A in a high risk population." BMJ 304(6821): 207-210.

Doherty, T. and N. Oliphant (2017). "Community based programmes: impact." World Nutrition. Fisker, A. and T. Greiner (2017). "HDVAC." World Nutrition.

Latham, M. (2012). "The great vitamin A fiasco." World Nutrition. 1:no.1: 12-24.

MacGregor, S., A. Tomkins, et al. (1992). Protein-energy Malnutrition, Hodder Arnold.

Macinko, J., F. C. Guanais, et al. (2006). "Evaluation of the impact of the Family Health Program on infant mortality in Brazil, 1990-2002." J Epidemiol Community Health 60(1): 13-19.

Mason, J., T. Greiner, et al. (2015). "Vitamin A policies need rethinking." Int J Epidemiol 44(1): 283-292.

Mason, J., K. Potts, et al. (2015). Analysis of the Nutrition Sector in Ethiopia. Tulane SPHTM https://tulane.app.box.com/s/zk9we8jykxm4emlz3ezo7ma217eahg99: 1-309.

Mason, J. B., T. Greiner, et al. (2015). "Reply to West et al. Vitamin A policies need rethinking." Int J Epidemiol 44(1): 294-296.

Mason, J. B., R. W. Hay, et al. (1974). "Treatment of severe malnutrition in relief." Lancet 303: 332-335.

McLaren, D. S. (1974). "The great protein fiasco." Lancet 2(7872): 93-96.

MI (2016) "Why Vitamin A." https://www.nutritionintl.org/what-we-do/bymicronutrient/micronutrientvitamin-a/.

Miller, D. S. and P. R. Payne (1961). "Problems in the prediction of protein values of diets: caloric restriction." J Nutr 75: 225-230.

Milner, K. M., T. Duke, et al. (2013). "Reducing newborn mortality in the Asia-Pacific region: Quality hospital services and community-based care." J Paediatr Child Health 49(7): 511518.

Minchin, M. (1987). "Infant formula: a mass, uncontrolled trial in perinatal care." Birth 14(1): 25-35. 
Scrimshaw, N. S., C. E. Taylor, et al. (1968). "Interactions of nutrition and infection." Monogr Ser World Health Organ 57: 3-329.

Shantha and R. Shrimpton (2017). "Community based programmes." World Nutrition.

Shukla, A. and S. Marathe (2017). "The Malnutrition Market: Let them eat paste." Economic and Political Weekly 52(25-6): 18-21.

Singh, P. and J. D. Sachs (2013). "1 million community health workers in sub-Saharan Africa by 2015." Lancet 382(9889): 363-365.

Sinha, D. P. and F. B. Bang (1976). "The effect of massive doses of vitamin A on the signs of vitamin A deficiency in preschool children." Am J Clin Nutr 29(1): 110-115.

Sommer, A., I. Tarwotjo, et al. (1986). "Impact of vitamin A supplementation on childhood mortality. A randomised controlled community trial." Lancet 1(8491): 1169-1173.

UNICEF (2007). Vitamin A supplementation: a decade of progress. NY, UNICEF.

Verguet S, J. W., Bertram MY, Tollman SM, Murray CJ, Jamison DT, et al. (2013). "Impact of supplemental immunisation activity (SIA) campaigns on health systems: findings from South Africa." Journal of Epidemiology and Community Health 67(11): 947-952.

Werner, D. and D. Sanders (1997). Questioning the solution. http://www.healthwrights.org/index.php?option=com_content\&view=article\&id=208:que s-solu\&catid=85, Healthwrights.

West, K., A. Sommer, et al. (2015). "Commentary: Vitamin A policies need rethinking." Int J Epidemiol 44(1): 292-294.

WHO (2010). Global Experience of Community Health Workers for Delivery of Health Related Millennium Development Goals: A Systematic Review, Country Case Studies, and Recommendations for Integration into National Health Systems. Geneva, WHO.

World Bank (2006). Repositioning Nutrition as Central to Development: A Strategy for LargeScale Action. Washington, DC, The World Bank.

World Health Organization (2013). Essential Nutrition Actions: Improving maternal, newborn, infant and young child health and nutrition. Geneva, WHO http://apps.who.int/iris/bitstream/10665/84409/1/9789241505550_eng.pdf. 